https://dx.doi.org/10.4314/ijs.v23i2.5

Ife Journal of Science vol. 23, no. 2 (2021)

\title{
MORPHOLOGICAL AND MOLECULAR ASSESSMENT OF MUSHROOM (Lentinus squarrosulus) (Mont.) SINGER
}

\author{
${ }^{1}$ Adenipekun C. O., *Ogunkanmi L. A., ${ }^{1}$ Onibonoje O. \\ ${ }^{1}$ Department of Botany, University of Ibadan, Nigeria. *Department of Cell Biology and, Genetics, \\ University of Lagos, Nigeria. \\ E-mail addresses of authors: ACO-clementinaadenipekun@gmail.com; OLA-logunkanmi@unilag.edu.ng; OO- \\ olusolaonibonoje2@gmail.com.*Corresponding author. \\ (Revision received: $12^{\text {th }}$ March, 2021; Accepted: $20^{\text {th }}$ May, 2021)
}

\section{ABSTRACT}

Lentinus squarrosulus is a popular mushroom in Nigeria used for traditional medicine apart from food. The identification of those high-quality fungal species is not only necessary but has great economic significance as it will allow product distributors to verify the material they are selling. Hence, this study investigated the morphological and molecular relationship among L. squarrosulus samples from different locations in Ibadan. Ten samples of L. squarrosulus were collected from nine different natural habitats in Ibadan, Oyo State, Nigeria, from which pure cultures were prepared. Isolation of DNA was done from fruiting bodies of fresh samples evaluated. Ten primers were designed from ITS sequences of the Family Agariceae and used for the study. The ten mushrooms evaluated in the study showed diverse morphological features such as colour of cap and pileus, size of stipe and pileus. A total of 50 amplicons were generated of which 31 bands (62\%) were polymorphic. The RAPD variety-specific products were generated in some of the genotypes evaluated which can serve as unique identifiers. The study showed mean values for marker gene diversity of 0.27 , Polymorphism Information Content (PIC) of 0.25 and $63.81 \%$ polymorphism. Both morphological and molecular analyses revealed two clustered groups. Number and types of samples in each group were not the same in both studies. The presence of unique band pattern among sampled fungi evaluated showed the discriminating power of the primer Ast-F in the study.

Keywords: Polymorphism, DNA, RAPD, Fungi, Gene diversity characterization

\section{INTRODUCTION}

Mushrooms are macrofungi which can either be hypogeous or epigeous with distinctive fruiting body (Chang and Miles, 1992). They are cultivated worldwide for their nutritional attributes, medicinal values and industrial applications ( $\mathrm{Lim}$ et al., 2004; Mata et al., 2005). Lentinus squarosulus is a popular mushroom used for traditional medicine in Nigeria and are edible due to the presence of proteins, lipids, fats, minerals, dietary fiber and vitamins (Fasidi and Kadiri, 1991; Chang and Miles, 2004; Okhuoya et al., 2005). The species of L. squarosulus species belongs to the PhylumBasidiomycota, Class- Basidiomycetes, OrderAgaricales, Family- Agaricaceae (Boer et al., 2004). It is commonly known as shiitake with tilted scales which includes the wood decaying species, characterized by decurrent lamellae, homoiomerous context, dimitic sporocarp tissues and hyaline elliptical spores (Yu et al., 2011). The protein content of this fungus has been reported to be double that of Irish potatoes and six times that of orange while its essential amino acid content exceeds that of kidney beans (Atikpo etal.,
2008). They are one of the higher valued nontimber forest products in Nigeria providing locals with seasonal food, medicine and an alternative income (Akpaja et al., 2003; Stamets, 2005; Ayodele et al., 2009; Sysouphanthong et al., 2010). The identification of mushroom in Nigeria has been by morphological examination which has led to erroneous identifications probably due to difficulties in distinguishing between genetically related species. Morphologically, mushrooms belonging to the same and even different genera may look similar and may need a more sophisticated tool to clarify.

Since indigenous mushroom resources are diverse and morphological identification are not sufficient for taxonomy (Collard et al., 2005; Urbanelli et al., 2007; Dentinger et al 2011), which may also be misleading because of environmental effect, a more reliable tool for characterization of mushrooms is therefore necessary. Through the advent of molecular marker technology, it is now possible to determine fungi based on their molecular data. The molecular markers, PCR 
(Polymerase Chain Reaction) and non-PCR based are widely used for mushroom identification and characterization (Das et al., 2013). Recently, the Internal Transcribed Spacer (ITS) of nuclear DNA has been proposed as the official bar coding marker for molecular identification of fungi (Henrion et al., 1992; Bellemain et al., 2010). The ITS regions of fungal ribosomal DNA (rDNA) are highly variable sequences of great importance in distinguishing fungal species. Hence the study aimed at investigating the morphological and molecular relationship among $L$. squarrosulus samples from different locations in Ibadan.

\section{MATERIALS AND METHODS}

\section{Sample Collection and Morphological Characterization}

Ten samples of L. squarrosulus were collected from nine different locations in Ibadan, Oyo State, Nigeria during the rainy seasons between May and July 2015 (Table 1). The samples were identified at the Mycology unit, Department of Botany, University of Ibadan, Ibadan, Nigeria, and were taken to International Institute of Tropical Agriculture (IITA) for further evaluations. The mushroom samples were characterized morphologically using the procedure described by Jonathan and Fasidi (2003)

\section{Pure Culture Preparations}

Pure cultures of L. squarrosulus were prepared according to the modified method of Adenipekun and Fasidi (2003). Pure and fresh cultures of the fungi were obtained by regular sub-culturing on Potato Dextrose agar.

\section{DNA Isolation}

The fungal DNA isolation from fruiting bodies of fresh samples of L. squarrosulus were carried out using the QIAamp DNA Mini kit according to the method of Magdum (2013) with modifications. Approximately $50 \mathrm{mg}$ of fresh mushroom samples were cut into small pieces and homogenized with homogenization buffer (50 $\mathrm{mM}$ Tris, $10 \mathrm{mM}$ EDTA and $50 \mathrm{mM}$ glucose). After homogenization, DNA was extracted using DNA extraction buffer- $100 \mathrm{mM}$ Tris, $10 \mathrm{mM}$ EDTA, $250 \mathrm{mM} \mathrm{NaCl}$ and 1\% Sodium Dodecyl Sulfate adjusted to $\mathrm{pH}$ 8.0. Proteinase-K was added and incubated in dry bath at $60^{\circ} \mathrm{C}$ for $1 \mathrm{~h}$.
After centrifugation at 3,000 $\mathrm{rpm}$ for $5 \mathrm{~min}$, supernatant was treated with equal volume of phenol:chloroform:isoamyl alcohol (25:24:1), incubated at $37^{\circ} \mathrm{C}$ for $10 \mathrm{~min}$ and centrifuged at $8,000 \mathrm{rpm}$ for $6 \mathrm{~min}$. The phenol:chloroform step was repeated and supernatant was collected. The DNA was precipitated using equal volumes of chilled isopropanol. The precipitate was washed with $70 \%$ ethanol and pure ethanol, dried, and resuspended in $50 \mu \mathrm{l}$ sterile water until needed. Resulting DNA samples were quantified by Nanodrop ND 1000 spectrophotometer (Thermo Scientific Inc., Wilmington, Delaware, USA) and qualitatively checked on 1.5\% agarose gel which was visualized in a Gel Documentation System LG 2020 (Hangzhou Langqi, Inco., China).

\section{Primer used}

The ITS sequences of the Agariceae family and of other species were investigated. Available nucleotide sequences ranging from 2 to $5 \mathrm{~kb}$ were downloaded from Gene Bank data base for primer design which resulted in the consideration of ten (10) primers (Len-F, Vol-F, Ama-F, Ast-F, Ter-R, Rus-R, Vol-R, Len-R, Vol-R and Rus-F (Henrion et al., 1992; Dentinger et al2011) for PCR detection of L. squarrosulus species. The closely related rDNA ITS sequences were retrieved from the DNA database using the BLAST program to verify the specificity of the primer pairs. The primer pairs were tested for sensitivity with total genomic DNA from 10 samples of fungi in PCR and a DNA fragment (approximately 300 bp) from the rDNA ITS gene was amplified. Diagnostic PCR was performed under the conditions mentioned below. The FASTA format of all those sequences was arranged in a file and then the sequences were aligned according to nucleotide homology using Cluster W software program.

\section{PCR Reactions}

Polymerase chain reaction was performed using the following: 10x PCR buffer $2.5 \mu \mathrm{l}$, dNTPs (25 mM of each) $2.0 \mu \mathrm{l}, \mathrm{MgCl}_{2}(25 \mathrm{mM}) 2.0 \mu \mathrm{l}$, forward primer $(10 \mathrm{pm} / \mu \mathrm{L}) 1.0 \mu \mathrm{l}$, reverse primer $(10 \mathrm{pm} / \mu \mathrm{l}) 1.0 \mu \mathrm{l}$, DNA template $10 \mathrm{ng}$ for each sample, Taq Polymerase $(2 \mathrm{U} / \mu \mathrm{l}) 0.5 \mu \mathrm{l}$, and DNase free water was used to adjust the volume to $25 \mu \mathrm{l}$. Amplification reactions were performed in 
the Corbett RG 6000 thermocycler using the following conditions: complete denaturation (94 ${ }^{\circ} \mathrm{C}$ for 5 mins), 10 cycles of amplification $\left(94^{\circ} \mathrm{C}\right.$ for $45 \mathrm{~s}, 32^{\circ} \mathrm{C}$ for $45 \mathrm{~s}$ and $72{ }^{\circ} \mathrm{C}$ for $45 \mathrm{~s}$ ) followed by 30 cycles of amplification $\left(94^{\circ} \mathrm{C}\right.$ for $30 \mathrm{~s}, 34^{\circ} \mathrm{C}$ for $30 \mathrm{~s}$ and $72{ }^{\circ} \mathrm{C}$ for $30 \mathrm{~s}$ ) and the final elongation step $\left(72{ }^{\circ} \mathrm{C}\right.$ for $\left.5 \mathrm{~min}\right)$. Electrophoresis of amplified products were run with $1 \mathrm{x}$ TAE buffer at $90 \mathrm{v}$ for $1 \mathrm{~h}$, visualized in the UV transilluminator and photographed in Gel Doc system (UVdoc H06, Cambridge).

\section{Analysis of Molecular Data}

Gel profiles were analyzed based on the presence or absence of individual bands, " 1 " indicating band presence while " 0 " indicating band absence. The genetic distance was calculated by the frequency similarity. The matrix of genetic distance was used for grouping the mushroom samples based on the dendrogram constructed by NTSYSpc version 2.02 (Rohlf, 1998). The optimal tree is drawn with the sum of branch length equal to 1.4246 . The tree was drawn to scale, with branch lengths in the same unit as those of the evolutionary distances used to infer the phylogenetic tree. The evolutionary distances were computed using the Maximum Composite Likelihood method and are in the unit of the number of base substitutions per site. Phylogenetic tree was generated on the basis of neighbour-joining method. The average number of alleles, gene diversity and polymorphic information content (PIC) values for markers were determined using PowerMarker version 3.25 (Liu and Muse, 2005).

\section{RESULTS}

The ten mushrooms collected from nine locations around University of Ibadan axis were identified as L. squarrosulus (Table 1). These fungi showed diverse morphological features such as colour of cap and pileus; size of stipe and pileus (Plates 110). Samples 1, 2, 5 and 6 possess whitish cap with short pileus, samples 8 and 10 had whitish pileus and long stipe. On the other hand, sample 4 possesses brown cap with short pileus, 9 had a brown pileus and long stipe while 3 and 7 had whitish cap with long pileus (Table 1).

Table 1: Provenance and Morphological Features of Lentinus squarrosulus Studied.

\begin{tabular}{lllll}
\hline ID & Location & DOC & Morphological features & IS \\
\hline 1 & Botany Department, UI & $14 / 04 / 2015$ & Whitish cap, stipe is short & L. squarrosulus \\
2 & Jaja Clinic, UI & $21 / 05 / 2015$ & White cap, stipe is short & L. squarrosulus \\
3 & Bodija, Ibadan & $15 / 06 / 2015$ & Whitish cap, pileus is long & L. squarrosulus \\
4 & Botanical Garden, UI & $07 / 07 / 2015$ & Brownish cap, Pileus is short & L. squarrosulus \\
5 & Nursery Farm, UI & $26 / 06 / 2015$ & Whitish cap, pileus is short & L. squarrosulus \\
6 & Moniya, Ibadan & $17 / 07 / 2015$ & White cap, pileus is short & L. squarrosulus \\
7 & Botanical Garden, UI & $07 / 07 / 2015$ & Whitish cap, Pileus is long & L. squarrosulus \\
8 & Sanyo, Ibadan & $22 / 07 / 2015$ & Whitish pileus, stipe is long & L. squarrosulus \\
9 & Zoological garden, UI & $22 / 07 / 2015$ & Brownish pileus, stipe is long & L. squarrosulus \\
10 & Alumni centre, UI & $06 / 08 / 2015$ & Whitish pileus, stipe is long & L. squarrosulus \\
\hline
\end{tabular}

Abbreviations: ID- Sample Identity; DOC- Date of collection; UI- University of Ibadan; IS- Identity of sample from Herbarium, UI. 


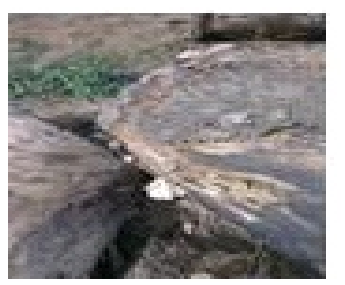

Plate 1: AG ventures, Botany Dept., UI

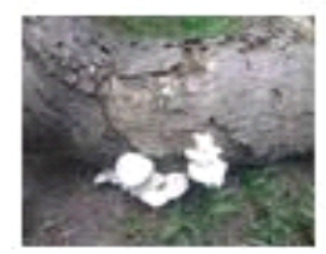

Plate 3: Bodija, Ibadan

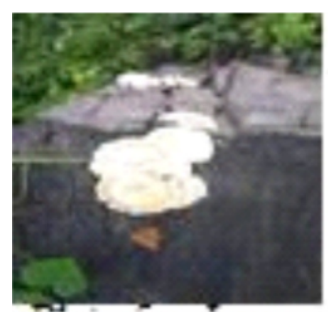

Plate 5: Nursery farm, UI

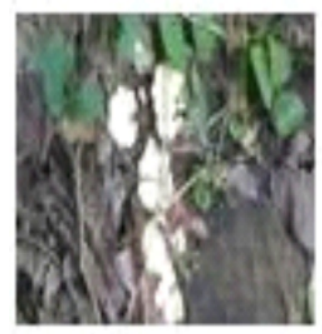

Plate 7: Botanical Garden, UI

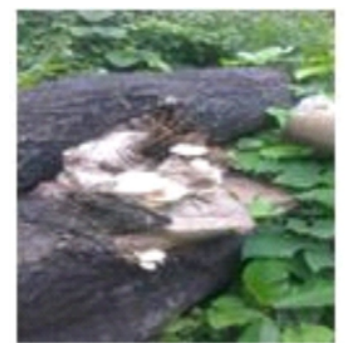

Plate 9: Zoological garden fence, UI

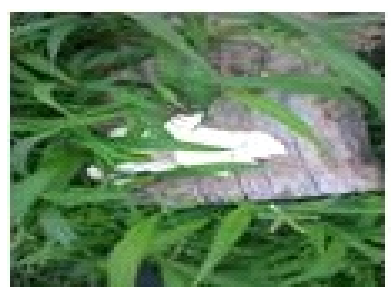

Plate 2: Jaja Clinic, UI

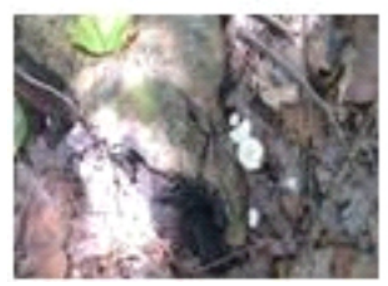

Plate 4: Botanical Garden, UI

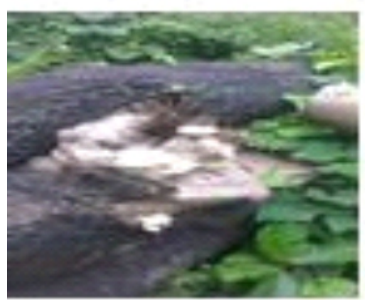

Plate 6: Moniya, Ibadan

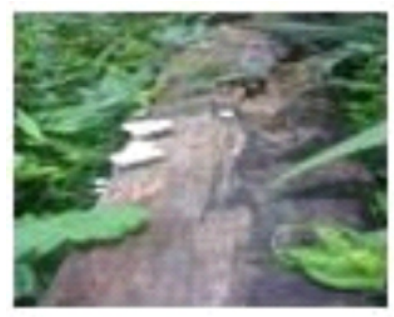

Plate 8: Powerline Sanyo, Ibadan

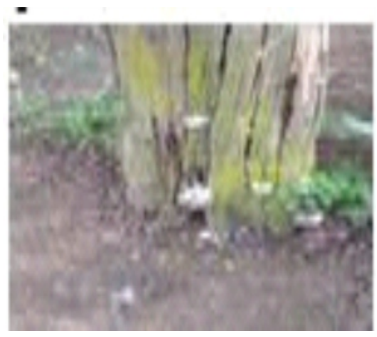

Plate 10: Alumni centre, UI

Plates 1-10: Growth Forms of Lentinus squarrosulus from the Field locations 


\section{Evaluation of Marker Performance}

Genomic DNA was successfully isolated from all the ten samples and the DNA regions were amplifed. The PCR products from the amplified DNA in the study were $1,100 \mathrm{bp}$ in size on $1.5 \%$ agarose gels, gave sharp and distinct bands which were used to construct a phylogenetic tree (Figure 2). A total of 50 amplicons were generated of which 31 bands (62\%) were polymorphic among the 10 primers used in the study. The highest number of bands was observed with primer Ter-R (10 bands) while Vol-F gave the least number of bands ( 2 bands) when evaluated with the sampled fungi. The Ast-F primer assay generated varietyspecific products in some of the genotypes (Plate 11).

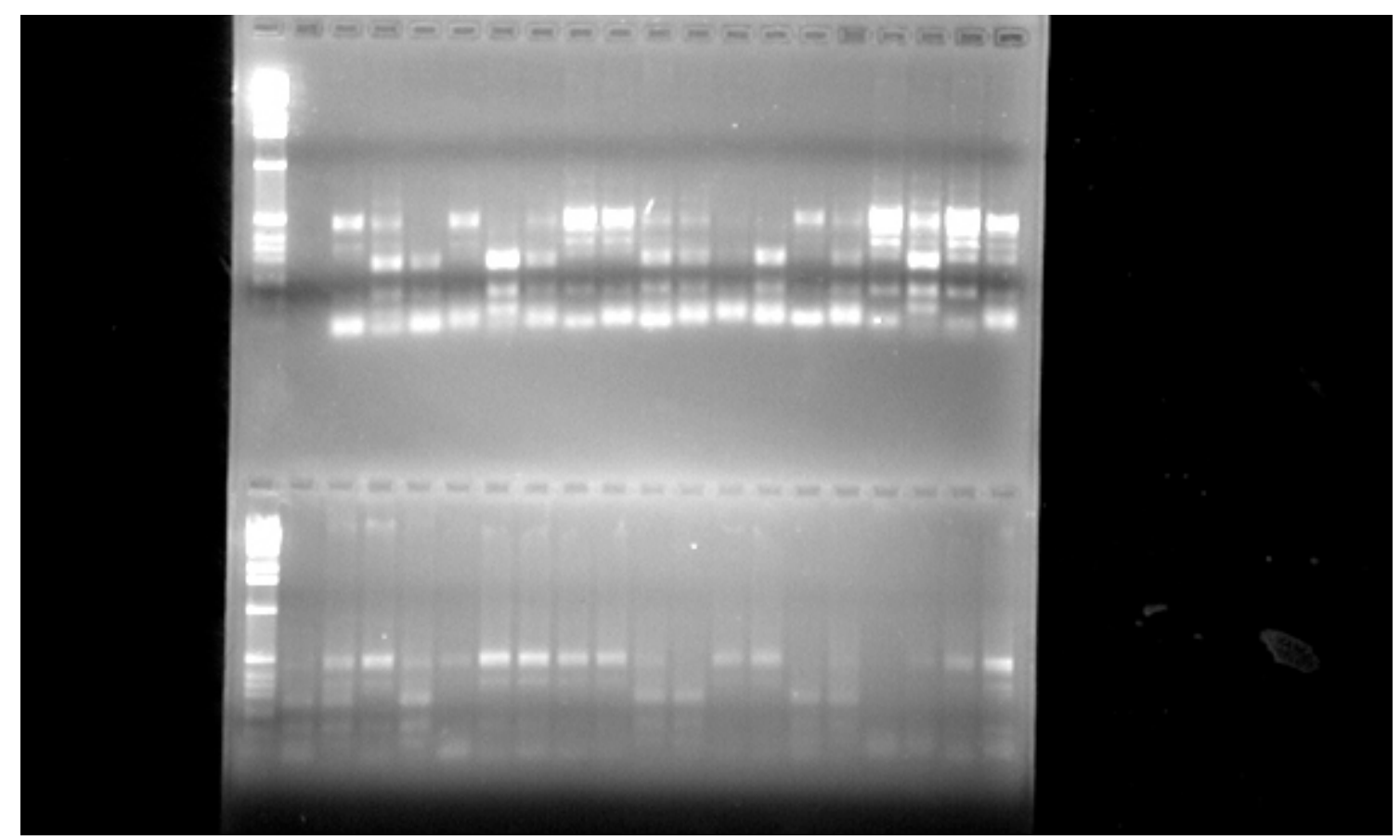

Plate 11: Gel Electrophoregram of Primer Ast-F with the Ten Samples of L. Squarrosulus $(M=D N A$ Ladder, $C=$ Negative control, 1-10 $=$ Samples $)$

The gene diversity values ranged from 0.11 to 0.44 with a mean value of 0.27 for markers used. Markers Len-R had the lowest values while marker Rus-R had the highest value. Only one marker Rus-R showed high heterozygosity. The Polymorphic Information Content (PIC) value ranged between 0.10 and 0.37 with a mean value of 0.25 among primers used. The total number of alleles amplified was 22. Although, average percentage polymorphic band was $63.81 \%$, both gene diversity and PIC values were however low (0.27 and 0.25 respectively) (Table 2 ). 
Table 2: List of Primers Used for the Study, their Sequences, Band Parameters and Gene Diversity

\begin{tabular}{|c|c|c|c|c|c|c|}
\hline Primer & Primer sequence & $\mathbf{N b}$ & $\mathbf{N p b}$ & $\begin{array}{l}\text { Ppb } \\
(\%)\end{array}$ & GD & PIC \\
\hline Len-F & $5^{\prime \prime}-$ GGA AGT AAA AGT CGT AAC AAG G-3' & 5 & 4 & 80 & 0.33 & 0.16 \\
\hline Vol-F & $5^{\prime \prime}-$ TCC TCC GCT TAT TGA TAT GC $-3{ }^{\prime}$ & 2 & 1 & 50 & 0.11 & 0.37 \\
\hline Ama-F & 5'-GTAAGTGCCGAATTCGAAATAACTGAATGGGA -3' & 2 & 2 & 100 & 0.36 & 0.10 \\
\hline Ast-F & $\begin{array}{l}\text { 5'-AGGGCTGTGGGATCCTCATTCAGGTCTATCACCTC - } \\
3\end{array}$ & 6 & 4 & 66.67 & 0.18 & 0.25 \\
\hline Ter-R & 5'-TCCTCCGCTTATTGATATGC -3' & 10 & 4 & 40 & 0.27 & 0.32 \\
\hline Rus-R & 5'- GGAAGTAAAAGTCGTAACAAGG -3’ & 7 & 5 & 71.43 & 0.44 & 0.29 \\
\hline Vol-R & 5'- -TCC GTA GGT GAA CCT GCG G-3' & 6 & 4 & 66.67 & 0.27 & 0.34 \\
\hline Len-R & 5'- -TCC TCC GCT TAT TGA TAT GC -3' & 4 & 2 & 50 & 0.11 & 0.33 \\
\hline Vol-R & 5' - GATGCCAGAC -3' & 3 & 1 & 33.33 & 0.42 & 0.22 \\
\hline Rus-F. & 5' - GAGAGCCAAC -3' & 5 & 4 & 80 & 0.18 & 0.10 \\
\hline Mean & & 5 & 3.1 & 63.81 & 0.27 & 0.25 \\
\hline
\end{tabular}

Abbreviations: Nb- Number of bands amplified; Npb- Number of polymorphic bands; PpbPercentage polymorphic bands; GD- Gene diversity; PIC- Polymorphic information content.

\section{Cluster Analysis}

The ten samples used in the morphological study were displayed on a dendrogram (Figure 1) on which all samples belonged to a single cluster at 0.18 similarity coefficient. However, when the dendrogram is truncated at 0.20 similarity coefficient, two major clusters were identified (Clusters I and II). Cluster I consists of seven samples $(1,2,3,4,5,6,7)$ with four sub-clusters.
Three out of the four sub-clusters consists of two tied samples each $(1 \& 2,5 \& 6$ and $3 \& 7)$ at 1.00 $(100 \%)$ similarity coefficients which means they were morphologically similar. The remaining subcluster consists of only one sample (4) clearly identified at 0.71 similarity coefficient. The second cluster consists of three samples (8,9 and 10) distributed in two sub-clusters. 


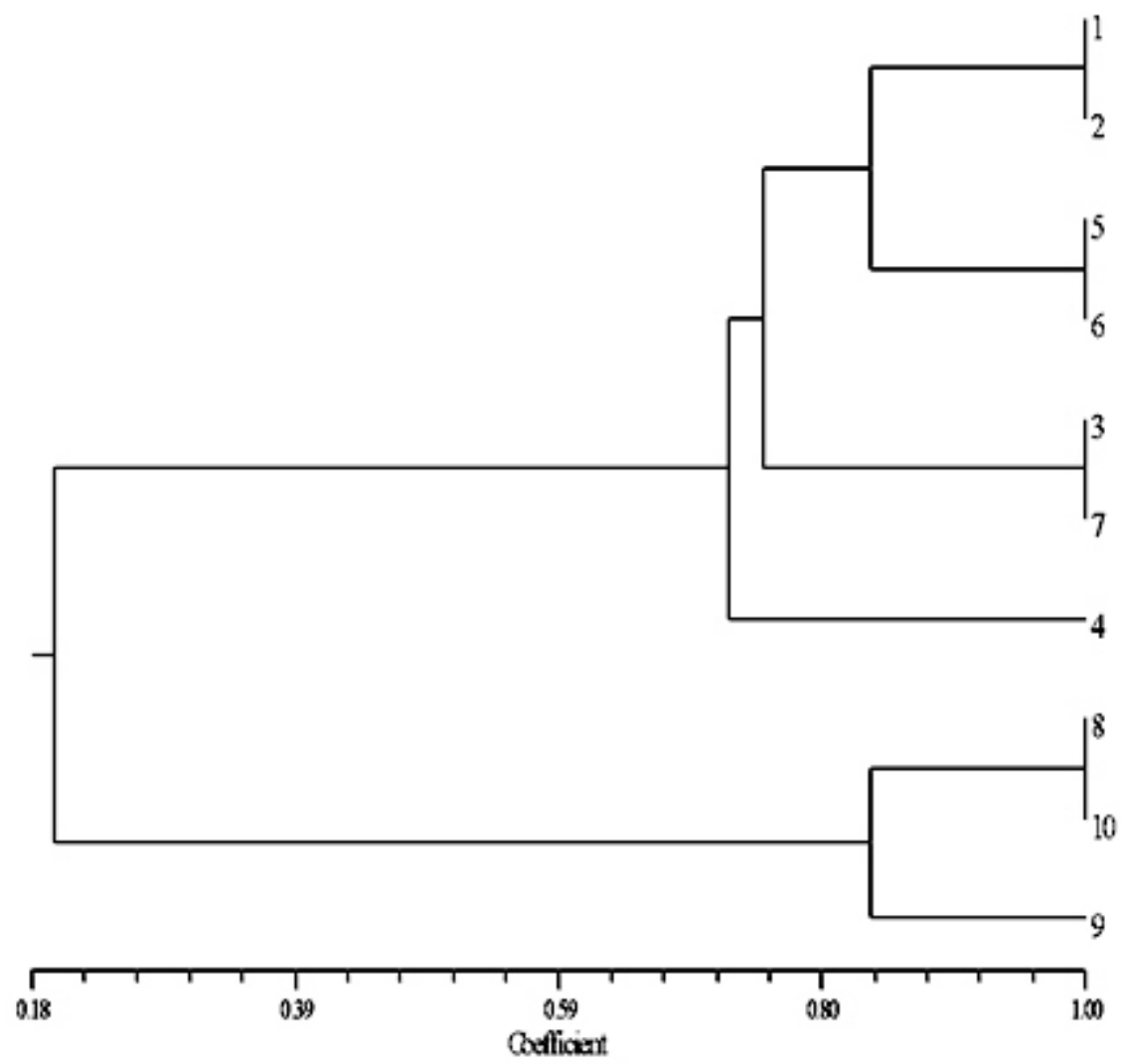

Figure 1: A UPGMA Dendrogram of the Ten Samples of L. squarrosulus Developed from the Morphological Data

The first sub-cluster consists of two tied samples $(8 \& 9)$ at $1.00(100 \%)$ similarity coefficient while the second sub-cluster consists of only one sample (9) which was clearly distinguished at 0.84 similarity coefficient. On the other hand, data generated from molecular analysis of the samples classified all the ten samples into one big cluster (Figure 2) at 0.50 similarity coefficient but when truncated at 0.55 similarity coefficient, two main clusters (clusters I and II) were identified. The first cluster consists of five samples $(1,3,4,8$ and 10) clearly distinguished at various levels of similarity coefficient. However, samples 1 and 3 appeared closer than any other samples at similarity coefficient of 0.88 . Cluster II also consists of five samples $(2,6,9,5$, and 7$)$ which were also clearly identified at various levels of similarity coefficient with samples 6 and 9 having a higher similarity (0.94) than others The highest similarity (0.94) was observed between samples 6 and 9 followed by the similarity (0.88) between samples 1 and 3 (Figure 2). 


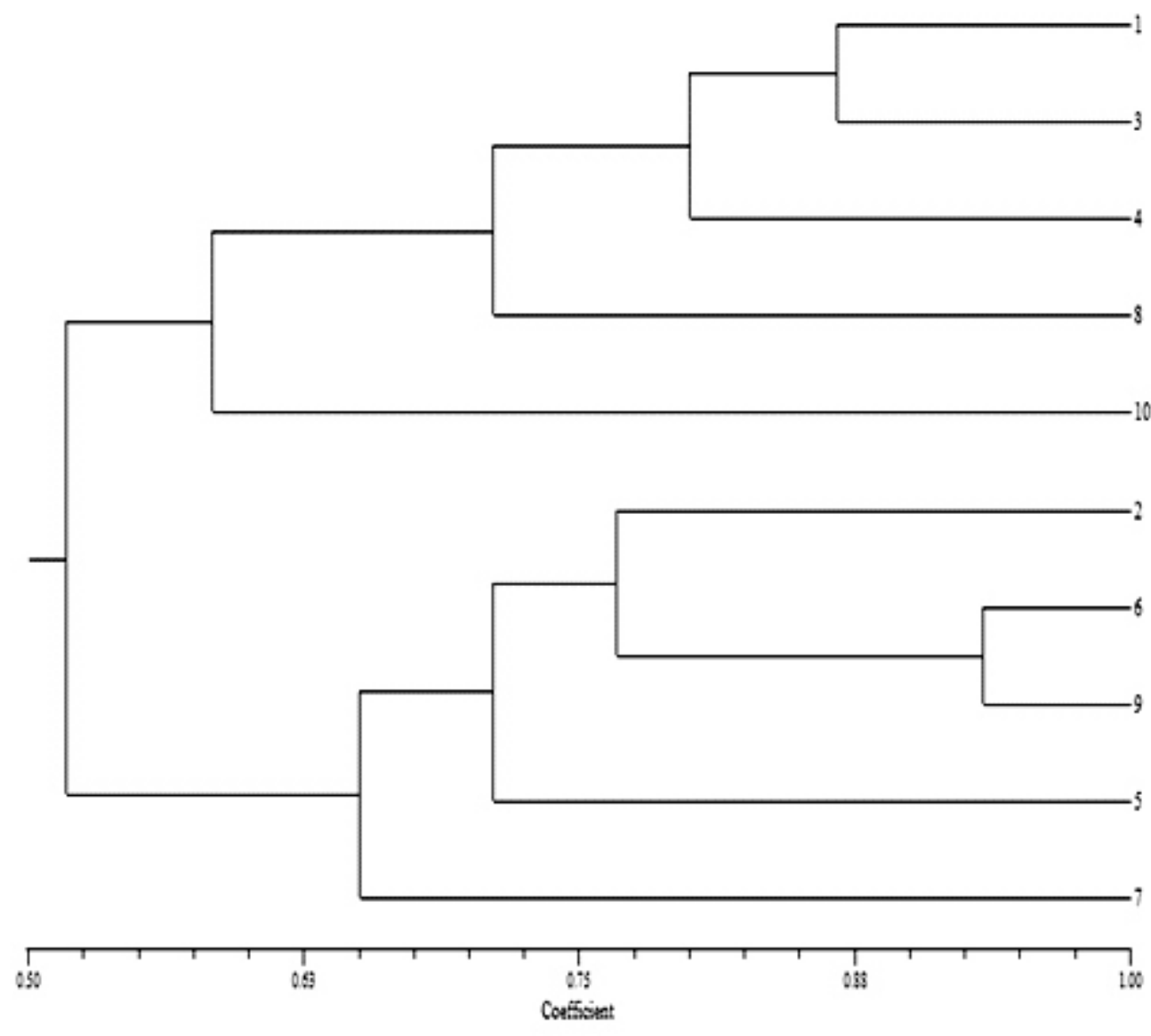

Figure 2: A UPGMA Dendrogram of the Ten Samples of L. Squarrosulus Developed from Molecular Data (1-10 = Samples).

\section{DISCUSSION}

With increasing demand for edible and medicinal fungal materials, the shortage of Nigeria edible and medicinal wild fungi has led to adulterants or substitutes for those precious fungi being sold fraudulently for high profit (Okhuoya et al 2010). Identification of those high-quality fungal species is not only necessary but has great economic significance as it will allow product distributors to verify the material they are selling (Osemwegie et al 2006). The variation in the number of bands amplified by different primers was influenced greatly by variable factors such as primer structure, template quantity and less number of annealing sites in the genome. This is similar to the findings of (Das et al. (2013) who reported variations in the number of bands amplified by different primers.

The length of the amplified DNA varied with primers used in the study. Similar length sizes have been recorded in 10 species of ectomycorrhizal fungi (Akpaja et al 2003). Molecular technology has been reported to greatly enhance detection sensitivity, as well as simplify and expedite the identification of organism (Collard et al., 2005). The presence of unique band pattern among sampled fungi evaluated with markers showed the discriminating power of the primers used in the study. This may be used as DNA fingerprints for variety identification and would be of immense use for the establishment of proprietary rights and the determination of variety purity. Several markers, including random amplified polymorphic DNA (RAPD), arbitrary primed PCR (AR-PCR), restriction fragment length polymorphism (RFLP), PCR-RFLP and DNA sequencing, have been used for the authentication of biological materials (Lakra et al., 2007; Bellemain etal2010).

Several authors have reported the discriminating advantage of molecular techniques over morphological evaluations. This is due to the fact that morphological features were prone to 
environmental manipulations while molecular particles which include DNA are not affected directly by the environment (Collard et al., 2005). Although, both morphological and molecular clustering revealed two groups, yet there were remarkable differences in the types and number of fungi samples in each group when compared clustering between morphological and molecular studies. Several studies have shown that morphological based grouping did not match molecular relationship among the species in most cases (Sambrook et al., 2001; Stajic et al., 2005; Tang et al., 2005). The result from the phylogenetic tree indicated that the samples are related species which is similar to results of restriction fragment length polymorphism (RFLP) amplification of the ITS region among different geographical fungal isolates within a species reported by Urbanelli, etal(2007).

\section{CONCLUSION}

From the results obtained, we can conclude that Lentinus squarrosulus are higher fungi and all of the ten random primers used in this study could be used as markers distinguishing the L. squarrrosulus. The polymorphic rates of some of the primers were almost alike, except for three primers (Len F, Ama F and Rus F) which have low value. The findings from this study showed that the use of RAPD marker could establish a relationship among $L$. squarrosulus samples based on gene diversity and polymorphism

\section{REFERENCES}

Akpaja, E.O., Isikhuemhen, O.S., and Okhuoya, J.A. 2003. Ethnomycology and usage of edible and medicinal mushrooms among the Igbo people of Nigeria. International Journal of MedicinalMushroom, 5:313-319.

Adenipekun, C.O. and Fasidi, I.O. 2003. Effect of animal manures on the growth and fruitbody production of Pleurotus sajor-caju on cassava peels. Advances in Food Science. 25: 125-129.

Atikpo, M., Onokpose, O., Abazinge, M., Louime, C., Dzomeku, M., Boateng, L. and Awumbilla, B. 2008. Sustainable mushroom production in Africa: A case study in Ghana. African Journal of Biotechnology. 4:1401-1403.

Ayodele, S.M., Akpaja, E.O., and Adamu, Y. 2009.
Some edible and medicinal mushrooms found in Igala land in Nigeria and their sociocultural and ethnomycological uses. Proceeding of The $5^{\text {th }}$ International Medicinal Mushroom Conference, Nantong, China. pp. 526-531.

Bellemain, E. Carlsen T, Brochmann C,. Coissac E, Taberlet P and. Kauserud H, 2010. ITS as an environmental DNA barcode for fungi: an in silico approach reveals potential PCR biases. BMCMicrobiology, 10(1): 189.

Boer, C. G., Obici, L., Souza, C. G. M. and Peralta, R. M., 2004. Decolorization of synthetic dyes by solid state cultures of Lentinus edodes producing manganese peroxidase as the main ligninolytic enzyme. Bioresources Technology, 56:1384-1387.

Chang, S.T. and Miles, P.G. 2004. Mushroom: cultivation, nutritional value, medicinal effects and environmental impact $\left(2^{\text {nd }} \mathrm{Ed}\right.$.) CRC Press, Boca Raton, 455pp.

Chang, S.T. and Miles, P.G. 1992. Mushrooms biology- a new discipline. Mycologist, 6: 6465.

Collard, B.C.Y., Jahufer, M.Z.Z., Brouwer, J.B. and Pang, E.C.K. 2005. An introduction to markers, quantitative trait loci (QTL) mapping and marker-assisted selection for crop improvement: the basic concepts. Euphytica, 142:169-196.

Das, S. Mandal A, Datta A.K., Gupta S. Paul R, Saha A, Sengupta S, and Dubey P.K., 2013. Nucleotide sequencing and identification of some wild mushrooms, Hindawi Publishing Corporation: The Scientific World Journal, 7 pages, Article ID 403191. https://doi.org/10.1155/2013/403191.

Dentinger, B., Didukh, M., and Moncalvo, J.M. (2011). Comparing COI and ITS as DNA barcode markers for mushrooms and allies (Agaricomycotina). PLoS ONE 6(9): e25081. http://dx.doi.org/10.1371/ journal.pone.0025081.

Fasidi, I.O. and Kadiri, M. 1991. Changes in nutrient content of Termitomyces robustus (Bech) Heim and Lentinus squarrosulus Berk during sporophyte development. Acta. Botanica Hungarica, 36: 167-172.

Henrion, B., Le Tacon, F. and Martin, F. 1992. Rapid identification of genetic variation of ectomycorrhizal fungi by amplification 
of ribosomal RNA genes New Phytologist, 122:289-298.

Jonathan, S.G. and Fasidi, I.O. 2003. Antimicrobial activities of two Nigeria edible macro-fungi: Lycoperdon pusilum (Bat. Ex) and Lycoperdon giganteum (Pers.), African Journal of Biomedical Research, 6: 85 90.

Lakra, W.S., Goswami, M., Mohindra, V., Lal, K.K. and Punia, P. 2007. Molecular identification of five Indian sciaenids (pisces: perciformes, sciaenidae) using RAPD markers. Hydrobiologia, 583:359363.

Lim, B.O, Yamada, K., Cho, B., Jeon, T., Hang, S.G., Kang, S.A. and Park, D.K. 2004. Comparative study on the modulation of Ige and cytokine production by Phellinus lintens grown on germinated brown rice, Phelinus linteus and germinated brown rice in murine splenocytes. Bioscience Biotechnology and Biochemistry, 68: 2391 2394.

Liu, K. and Muse, S.V. 2005. PowerMarker: an integrated analysis environment for genetic marker analysis. Bioinformatics, 21: 2128-2129.

Mata, G., Hemande, D.M. and Andreu, L.G. 2005. Changes in lignocellulolytic enzyme activities in six strains cultivated on Coffee pulp in confrontation with Trichoderma spp. World Journal of Microbiology and. Biotechnology, 21:143-150.

Magdum S.S. 2013. A Reliable and High Yielding Method for Isolation of Genomic DNA from Ammi majus, International Research Journal of Biological Sciences, 2: 57-60.

Okhuoya, J.A., Akpaja, E.O., and Oghenekaro, A. 2005. Cultivation of Lentinus squarrosulus (Mont.) Singer on sawdust of selected tropical tree species. International Journal of. Medicinal Mushrooms, 7: 440-441.

Okhuoya, J.A., Akpaja, E.O., Osemwegie, O.O., Oghenekaro, A.O., and Ihayere, C.A.
(2010). Nigerian Mushrooms: Underutilized Non-Wood Forest Resources. Journal of Applied. Science and EnvironmentalManagement. 14(1): 43-54.

Osemwegie, O.O., Eriyaremu, E.G., and Abdulmalik, J. (2006). A survey of macrofungi in Edo/Delta region of Nigeria, their morphology and uses. Global Journal of Pure and Applied Science, 12(2): 149-157.

Rohlf, F.J. 1998. Numerical Taxonomy and Multivariate Analysis System. Applied Biostatistics Inc., New York, 37pp

Sambrook, J.D., Russell, W. and Sambrook, J. 2001. Molecular cloning: a laboratory manual (3rd ed.) NY: Cold Spring Harbor Laboratory Press, Pg 16.1-16.81.

Stajic, M., Sikorski, J., Wasser, S.P. and Nevo, E. 2005. Genetic similarity and taxonomic relationships within the genus Pleurotus (higher Basidiomycetes) determined by RAPD analysis. Mycotaxon, 93: 247-255.

Stamets, P. 2005. Mycelium Running: How mushroom Can Help Save the World. Berkeley, CA: Ten Speed.pp. 57.

Sysouphanthong, P., Thongkantha, S., Zhao, R., Soytong, K. and Hyde, K.D. 2010. Mushroom diversity in sustainable shade tea forest and the effect of fire damage. Biodiversity Conservation. doi: 10.1007/s10531-009-9769-1.

Tang, B.H., Wei, T.Z. and Yao, Y.J. 2005. Type revision of three Termitomyces species from India. Mycotaxon, 94: 93-102.

Urbanelli, S., Della Rosa, V., Punelli, F., Porretta, D., Reverberi, M., Fabbri, A. A., and Fanelli, C. (2007). DNA-fingerprinting (AFLP and RFLP) for genotypic identification in species of the Pleurotus eryngii complex. Applied Microbiology Biotechnology, 74: 529-600.

Yu, C.X., Cao, H. and Cheng, B.B. 2011. Mating type factors of L. squarrosulus. Acta Edulis Fungi, 17:5-7. 